[Aikin, S. (1995). Primary Problems and the New Zealand Curriculum Framework. New Zealand Annual Review of Education, 4, 57-76]

\section{Primary Problems and the New Zealand Curriculum Framework}

\section{SANDRA AIKIN}

\section{Abstract:}

Selected features of the New Zealand curriculum framework are examined and their relevance to, and potential impact upon, primary schools considered. Because every school is a medium through which the implementation of curriculum policy must pass, these features are examined within the context of primary school culture.

The argument is made that despite attempts to make the framework appropriate to primary school teaching methods and values, there are contradictions in the framework that inevitably favour secondary schooling and, by extension, the labour market. As a result, the framework has the potential to jeopardise many valuable aspects of primary school.

\section{The New Zealand Curriculum Framework (the framework)}

New Zealand research (see Ramsay et al., 1994) on the impact of the framework is just beginning to emerge. A great deal can also be learnt by considering the national curriculum debate in England and Wales. Some clear differences exist between their respective curriculum developments, but there are also some "striking similarities" (Sutton, 1994:334)

The New Zealand Curriculum Framework sets out the foundation policy for teaching, learning and assessment in New Zealand schools. Its development was the result of extensive reviews of curriculum and assessment policies that had been carried out in the 1980s. The framework was closely linked to the National Government's key educational policy, the Achievement Initiative (Ministry of Education, 1993a:1).

The framework describes the elements which are fundamental to teaching and learning programmes. To this end it:
58 Sandra Aikin

- $\quad$ states the principles which give direction to all teaching and learning;

- $\quad$ specifies seven essential learning areas which describe in broad terms the knowledge and understanding all students need to acquire;

- $\quad$ sets out the essential skills to be developed by all students; and

- indicates the place of attitudes and values in the school curriculum (Ministry of Education, 1993a:4).

A series of supporting documents, national curriculum statements, provide details for teachers' guidance on the required knowledge, understandings, skills and attitudes in each learning area.

The framework sets out the dimensions of these statements. Within each of the statements several strands of learning are identified, each with one or more achievement aims which are further subdivided into sets of specific objectives (known as achievement objectives) (Ministry of Education, 1993a:22).

Apart from the language used and the greatly increased number of specific objectives specified, the curriculum planning structure of major areas of learning, aims and objectives continues to follow past practice. A radical departure from past practice, however, appears with the achievement objectives.

These are set out in a number of progressive levels (usually eight), with assessment procedures designed to provide information on student achievement against these objectives. The information recorded from the assessments can then be used to build a profile of individual achievement.

It is this model of "progression" determined by assessed achievement on a linear and hierarchical route that appears to conflict with the "childcentred" approach espoused by primary teachers in New Zealand.

\section{Assessment}

The notion of individual achievement is a crucial one to the development of a child's learning profile outlined by the framework's achievement objectives and "levels". The emphasis is upon "progression of desirable standards of learning, throughout the years of schooling, against which students' progress can be assessed" (Ministry of Education, 1993a:3). Such an approach presupposes a clear view of what constitutes progression in each area under consideration. This is a potential stumbling block when it comes to concepts such as imagination. 
Elley (1993:45) questions how teachers can reliably assess students' progress in achieving important academic skills when those skills are not easy to specify in steps.

Where, then, did the notion of profiling come from? Hicks (1986:22) offers one explanation. She claims that "reservations concerning the examination system at senior secondary school level have influenced the direction of the profiling movement". She attributes the growth of profiling systems to an attempt to accommodate the needs of a substantial minority of school leavers who leave school with "nothing to show for 11 years of compulsory education".

Nonetheless, profiling has considerable potential for development in primary schools, as Hicks' review indicates, particularly in the area of increased student motivation and an improved quality of classroom assessment.

New Zealand school-based assessment activities, unlike those in England and Wales, remain broad and depend upon the judgements of teachers. But, for a number of reasons relating to the approaches used for assessment, the model of learning set out in the framework may have damaging effects upon primary programmes and practice.

In New Zealand primary schools, assessment practices are in line with good practice identified by research (Crooks,1989; Dweck, 1989) on what works effectively to improve learning in relation to particular curriculum and social goals held for children (Wylie and Smith, 1993:151). Primary teachers had strongly emphasised monitoring the learning process (diagnostic assessment) rather than focusing on an "end" result (summative assessment).

Clearly, in an environment which stresses accountability, there is the potential for "levels" of achievement to become curriculum performance indicators to be used for public reporting on a school's effectiveness. The focus and use of assessment then becomes critical to the "end" result and not the process.

In implementing the model of criterion-referenced, age-independent "levels", teachers are expected to take account of the differing abilities of children. If each "level" of learning corresponds to approximately two years, the range of achievement in a class at a given age may be as much as six years. Brehony $(1990: 125)$ reflects that historically teachers have responded to mixed-age classes by streaming. Brehony supports Gipps's (1988) appraisal that "the most likely response of schools to this knowledge is that they will set and stream more". A return to streaming would negate current primary school practice and its proven value.
Another assessment strategy plan at a national level is for assessment resource banks. Such a development is intended to produce nationally validated tasks at the key transition points (forms 1 and 3). These tasks will be closely related to the curriculum statements. Currently the intention is that schools will select the items that assist them to measure their school-based objectives in curriculum against national standards. The Ministry of Education has an interest in maintaining a core of compulsory items which will provide information about standards across the country. Because of the potential to report the information in "league table" form, it is inescapable that teachers will teach to the content of the items that the Ministry requires to be included. If the resource bankitems do become of paramount importance, then the approach to teaching is likely to become more formal and subject-based in response to perceived accountability measures.

Are these problems for primary school practice inevitable? Probably not, if there were not also a requirement for aggregated results. As Wylie (1994:120) succinctly states:

The increased accountability of individual schools in the current forms of accounting for public money puts emphasis on demonstrating results, and hence encourages the use of aggregated children's individual achievement data to provide such evidence.

\section{Educational Politics and Curriculum Policy}

Curriculum issues are not just "educational". They are located within the wider context of public and political debates. It is those debates which carry more weight in curriculum policy construction, rather than the more conventional education frameworks such as how children learn (Moore \& Ozga, 1991:4). This creates a tension for primary teachers and challenges the culture of primary schools.

The New Zealand education administration reforms did not arise out of widespread dissatisfaction with the education system (Wylie, 1994:xvi), i.e., the how of children's learning. For example, a Heylen public opinion poll conducted in November 1987 identified the shortage of teachers, resources and funds as the main problems in New Zealand education (schools), not the quality of the curriculum or its delivery This poses questions about the relationship of the reforms to curriculum policy and what exactly the changes are intended to achieve in primary schools.

Politicians, some public officials and business leaders (see, for example: Richardson, 1987; New Zealand Treasury, 1987; Irwin, 1994) 
perceived a gap between the current academic performance of students and the future economic, political and social needs of the country. Schools became the setting for economic and social concerns "arising from structural adjustment, employment changes, new ethnic patterns in population and the change from prescriptive value systems..." (OECD, 1994:15).

Criticism of the New Zealand education system from the "right" was part of a much wider concern apparent in many OECD member countries. The perception of a "gap" between performance and need was generated by an international economic crisis, and school curriculum became a topic for national policy debate. OECD member countries moved towards a more performance-based view of curriculum policy. Elmore \& Fuhrman (1994:1) contend:

the debate increasingly focuses on curriculum as one mechanism for improving student performance, measured against national goals and international standards of achievement.

Interestingly, the OECD report, Schools and Quality (1989), in its discussion of curriculum content and the nature of core learning, focuses very strongly on secondary education and largely ignores the primary area (Chapman et al., 1991:106). This focus on secondary education reveals a greater degree of attention now being paid to the qualities possessed by the labour force and the ability to produce high quality goods and services (Istance and Lowe, 1991:29).

In New Zealand there was a sustained period of criticism on aspects of the education system such as inequalities of achievement, maintenance of standards and the allocation of resources (Codd et al., 1990:7). The theme of "accountability" was stressed by the New Zealand ministerial taskforce (Taskforce to Review Education Administration, 1988:43 - known as the Picot Report). At the same time, debate was initiated at a national level on a curriculum-linked assessment policy with the release of a public discussion document which set out the major issues involved in assessment (Ministerial Working Party, Assessment for Better Learning, 1989).

Curriculum and evaluation practices had not been included in the Picot taskforce's (1988:ix) terms of reference. In spite of that, David Lange, then Minister of Education (in his preamble to the Tomorrow's Schools policy document), represented the reforms as providing a guide to a school's educational operation leading "to improved learning opportunities for children" (Lange, 1988:iv). The perception of most principals was contrary to Lange's view. In the Monitoring Today's Schools research (Mitchell et al, 1993:81), principals in case-study schools saw the policy's emphases on student learning and quality teaching "as a continuation of well-established philosophies".

\section{General Support for the Introduction of a Curriculum Framework}

There has been general support from primary teachers and primary boards of trustees for the introduction of a New Zealand curriculum framework (NZEI, 1991; Donn \& Bennie, 1992; Mitchell et al., 1993; Wylie, 1994). Teachers' commitment to the framework, however, is not unqualified. The national curriculum objectives and some areas of assessment were considered contentious, and for some items support was conditional upon certain other conditions being met, e.g., provision of resources (Donn \& Bennie, 1992:16).

The framework was introduced at a time when the consequences of school-based management, the gradual weakening of support structures (special education and advisory services), and new requirements for auditing and reviewing of schools were all beginning to impact upon primary school organisation and resourcing.

A nationally set curriculum was not new in New Zealand, as Wylie (1994:113) explains:

New Zealand teachers were accustomed to a national curriculum which gave primary schools flexibility in what they covered, and when, within an overall set of guidelines.

Primary teachers felt much of what was being proposed in the draft New Zealand National Curriculum Discussion Document (Ministry of Education, 1991) was already being carried out in schools (Donn \& Bennie, 1992:17; Mitchell et al., 1993:82). This attitude contributed to a belief that, by adapting current practices, the requirements of the framework could be incorporated into existing practice.

Survey results (Wylie, 1994:121; Mitchell et al., 1993:80) of curriculum changes which have taken place since the reforms support this belief. Few signs of radical change in curriculum and assessment are evident. Wylie (1994) attributes most of the curriculum changes evident to developments started either prior to the reforms, or to provision at the national level.

My perception is that the likely impact of the framework runs counter to what, in the past, has been regarded as the ideal model of curriculum and pedagogy for primary schools. Faced with a threat to 
their philosophy and culture, primary teachers may resist many changes the framework proposes, including the more positive, educationally progressive ones. In addition, I argue, the contradictions inherent in the framework suppress primary philosophy and successful practices in order to accommodate those of secondary schooling.

The challenge for primary schools will be to reconcile the individual, child-centred approach to teaching and learning, with system requirements for age-related content and assessment.

\section{Primary School Philosophy and Culture}

Before exploring in more depth some of the pressures exerted by the framework on primary practice, I wish to assist understanding of why there may be resistance to "imposed" policy changes, by highlighting the distinctive philosophy and culture already long-standing in primary schools.

The typical approach of New Zealand primary schools to the curriculum is to view it as a set of learning experiences, usually determined by teachers, which shape and refine children's existing knowledge, interests and experiences. It is "liberal" in giving a broad range of experience through a variety of teaching and learning styles, and "pragmatic" in building on, and extending, much current practice through careful planning of aims and content (McDonald et al., 1992).

Every school has an accepted practice or method, and underlying values, which influence programmes of teaching and learning for its students. Despite needing to be wary of generalising about more than 2300 New Zealand primary schools, there are common features which affect policy implementation. Campbell and Emery (1994:13), writing in the context of the recent education reforms in England and Wales, identify five such features. Three are adapted from Evetts's (1990) writings on "workplace culture". These are:

- Small size, and therefore close, regular daily contact between all teachers in an organisation fairly well insulated from others, which does not tolerate too much conflict.

- Conceptions of the job as largely generalist and welfare in orientation, with low levels of perceived specialist competencies or professionalism.

- Gender (teacher) imbalance, with its implied heavy burden of domestic work outside school for most teachers.
To these three, Campbell and Emery add a further two attitudinal characteristics: "a high cultural premium on demonstrated conscientious effort", and "high levels of deference to perceived educational authority."

The features identified by Campbell and Emery's analysis are characteristic of the New Zealand scene too, although a subtle difference apparent in the final characteristic should be noted. New Zealand primary school teachers are reluctant to openly challenge perceived authority directly rather than deferring to it.

Campbell and Emery say that it would be wrong to underestimate the strength of resistance to change in school cultures. This would also be true of New Zealand primary school cultures if "change" were imposed from "outside" and did not appear to benefit children'slearning directly.

\section{Levels of Achievement}

The New Zealand Education Gazette (16 April, 1991) detailed the main elements of the Government's key educational policy, the "Achievement Initiative". One of those elements was:

the establishing of clear achievement standards for all levels of compulsory schooling, first in the basic subjects of English, mathematics, science and technology, and later in other subjects.

Approximately one-fifth of both primary school and board of trustees (primary and secondary) respondents, did not answer the question on "levels" in Donn and Bennie's (1992:31) analysis of responses to the draft New Zealand National Curriculum Discussion Document (1991). Donn and Bennie surmise that this was a strong indication that respondents may have had difficulties with the concept of "levels" of achievement.

In theory, the "levels" offer an obvious and straightforward statement of progression: a child moves through the different "levels" at his/her own pace. In practice, there are serious problems (Elley, 1993) with the attempt to define a child's increasing mastery of knowledge, understanding and skills against "levels" considered to be typical for his/ her age. In addition, there are organisational difficulties for primary teachers. Even in the ideal primary class of $15-25$ children, teachers are likely to have reservations about teaching to "levels" since this approach is contrary to their understanding of how children learn.

Such difficulties, set within the established culture of primary schools, immediately establish the "levels" of achievement as an area of potential conflict between policy requirements and professional knowledge. 
Brehony (1990:115) contends that in a curriculum approach based on learning progression, the question of how children learn is virtually ignored in favour of an approach which focuses almost entirely upon knowledge and skills. I would add that the approach focuses only on the observable and measurable aspects of knowledge and skills - which are limited.

The contentious "top-down" approach Skilbeck (OECD, 1994:15) warned about, is evident. The secondary sector national examination perspective dictates the content and progression of the primary school curriculum. Courses designed for senior students are required to have longterm creditworthiness for vocational careers and further study. The vocational pathway must lead on to post-sixteen education and training opportunities (OFSTED, 1994:6). Inevitably that pathway subordinates the aims and practices of primary school to those of the secondary school and, by extension, to the requirements of the labour market.

Black (1993) argued against criticism that a "levels" system assumes a particular learning theory:

Anyone planning teaching has to have some way to decide in what order pupils' thinking should be helped to develop - it is inconceivable that a subject's teaching be planned without some model of progression as a basis.

But New Zealand primary teachers had developed their own models of learning based on individual progress:

Most teachers appeared to be operating within a learning-goal framework of children's learning, which is based on a model of progress which is multidimensional and spiral, rather than linear, and based on performance goals. The teachers' model fits their classroom organisation patterns, and curriculum and assessment resources and structures. It is also well supported by the research literature (Wylie \& Smith, 1993:viii)

Primary schools have differed from secondary schools in what and how they teach, because of the physical, emotional and learning needs of children in that age range. In primary schools, the child-centred approach means children are encouraged to construct their own meanings, and the teacher's key task is to mediate and provide opportunities to enrich learning. When efforts are made to define learning outcomes in behaviourist-orientated unit standards, the dilemma of contradictions between primary practices and the principles of the framework is apparent.
The framework's principles seek to ensure that the day-to-day practices of schools reinforce the formal curriculum. One principle urges teachers to ensure the school curriculum "be sufficiently flexible to respond to each student's learning needs" (Ministry of Education, 1993a:6).

In practice, the impact of using assessment to determine "levels" of achievement, and the requirement on a school to report on that achievement in accordance with public accountability objectives, mean that the framework's principle is unlikely to ensure the more flexible child-centred approach of the primary school can be maintained.

\section{Subject-Based Organisation}

Subject categories to describe primary school curriculum have been used since the 1940s. In practice, primary schools have moved away from a subject-based teaching approach. An increased awareness that learning takes place best in a holistic form, and the need to cover more and more syllabuses, have led to more integration of topics, with subject names largely abandoned in primary schools.

The framework's potential to return to a "subject-based" approach was recognised by some of the respondents in the Monitoring Today's Schools research (Mitchell et al., 1993:82). Concern was expressed that the draft New Zealand National Curriculum Discussion Document (Ministry of Education, 1991) might "encourage greater compartmentalisation of the school curriculum and thus undermine the more integrated approach that many schools now favour".

The Ministry policy project team developing the framework tried to ensure that the essential learning areas would be inclusive of primary school tradition and understanding. Of the seven learning areas, only three are expressed in the traditional subject-based manner: those of mathematics, science and technology These subjects reflect the Minister's priorities for curriculum policy development and link directly to labour market requirements.

In addition, a closer examination of the essential learning area Language and Languages also reveals political pressure for extending an academic focus and subject hierarchy (Lee \& Lee, 1992:33).

"Language is a primary teaching term for integrated spoken and written language development. An essential learning area named Language and Languages certainly appears sympathetic to the holistic approach taken by primary schools. The Ministry contract for the 
development of the curriculum statement, however, required the statement to reflect "the best of English teaching practice in New Zealand". When the draft statement was circulated for comment, the subject orientation was signalled in the title, English in the New Zealand Curriculum Draft (Ministry of Education, 1993b).

With the subsequent release of other draft language statements such as Spanish, Chinese and Samoan, reinforced by curriculum-teacher development contracts let in English, the Ministry of Education showed it had opted for the traditional subject division approach. Allowing schools the opportunity to set up programmes that deal with what is common to all language learning, but which could be fitted into a national policy framework, would have been more helpful to primary schools (NZEI, 1994a).

There is a studied ignoring of the growth of contemporary primary practice: the generalist culture primary teachers work within is most at risk with a subject-based approach which will continue to make their experience invisible.

Furthermore, Weston et al. (1992:16) emphasise the dangers of ignoring the primary experience and warn that:

if the subjects are the bricks, there is a danger that cross-curriculum elements become an additional, even a competing, set of curriculum priorities rather than the medium for binding the curriculum into one coherent whole.

This is already evident with the labelling of technology as an essential learning area in its own right, rather than the primary approach of integrating and incorporating technology across every curriculum area.

By favouring traditional secondary school organisation, the fragmentation of the curriculum at both primary and secondary levels is secured.

\section{Curriculum Expertise}

Associated with the indirect encouragement of more subject-based teaching has been the tendency to call for increased subject specialisation. Debate over curriculum expertise in the primary sector is not new. There is a perception that primary teachers may know how children learn and develop, but lack the subject content and the confidence necessary to implement some areas of the curriculum, for example, science. There are three related issues involved: first, the depth of subject knowledge needed by class teachers if they are to teach and assess confidently; second, the number of subjects in which that knowledge is required; and third, whether some form of specialist or semi-specialist teaching would help.

Given the range of curriculum areas a primary school teacher is expected to have content knowledge of, increased specialist teaching has its attraction, although it poses a challenge to the generalist primary teacher.

Lee and Lee (1992:19) claim that the draft New Zealand National Curriculum Discussion Document (Ministry of Education, 1991) has “... seriously underestimated the persistent problem of attempting to balance general education requirements against the push for early specialisation...."

In the debate in England and Wales on their national curriculum, Alexander, Rose and Woodhead (1992) set what was their view of requirements for providing quality primary teaching. Included in this set was teachers' subject knowledge:

Teachers must possess the subject knowledge which the Statutory Orders require. Without such knowledge, planning will be restricted in scope, the teaching technique and the organisational strategies employed by the teacher will lack purpose, and there will be little progression in pupils' learning (para 120).

The subject knowledge required by the National Curriculum makes it unlikely that the generalist primary teacher will be able to teach all subjects in the depth required (para 121).

What are the future scenarios for New Zealand primary schools if WE accept that this analysis is correct?

Bennett et al. (1994:35) question whether in fact primary schooling can attract specialists, particularly in science. These researchers point out that the size of many primary schools is such that the scope for specialist staffing is limited.

An alternative would be to enable teachers with subject specialist knowledge to work alongside colleagues, similar to the advisory services model that is current in New Zealand. This would allow for nonspecialist teachers to have their content knowledge and pedagogy extended within school-based in-service education and training.

Unfortunately, professional advisory support to primary schools has decreased since devolution. This is due primarily to: 
- continuing uncertainty about the future of the advisory services, which has led to a loss of staff;

- funding arrangements that allow the advisory service employers to use the funding flexibly rather than devote that funding specifically to adviser salaries when an adviser's position becomes vacant; and

- advisory services now putting more resources into secondary school support, where it is perceived that increased specialist help is required.

A further difficulty is that, for the most part, the entitlement staffing of primary schools does not provide for non-contact time within the timetable day so that primary classroom teachers can share their expertise with colleagues within their own school. The Minister of Education has acknowledged that a primary staffing review is long overdue, but only recently have Ministry officials been instructed to take stock of existing gaps in the primary system.

So, where does this leave primary schools? The expectations of the framework are longterm; but in the short term it is likely that primary teachers' perceived lack of specialist competencies will influence them because they are conscientious and intent on doing their best for the children in their class) to rely increasingly upon commercial materials to implement the requirements of the framework. With the implementation of the mathematics curriculum statement, this has already been the experience of schools within the Manawatu area (NZEI, 1994b).

\section{A Broad and Balanced Curriculum}

The first principle (Ministry of Education, 1993a:6) of the framework requires all students to be given the opportunity of a "broad and balanced" education throughout their years of schooling. This principle is emphasised in the essential learning areas (Ministry of Education, 1993a:8-9).

While the importance of the attempt to guarantee scope and balance in the curriculum should not be underestimated, there may be questions about how well this goal can be achieved in practice by primary schools. The notion of a broad and balanced curriculum is more appropriate for secondary schools, as it is tightly related to providing increased opportunities for senior students seeking qualifications and employment:
The curriculum experienced by students aged 14-16 should not lock them into a particular vocational direction thereby unduly restricting choices at 16+ (OFSTED, 1994:15).

It is difficult to judge precisely how primary teachers, working mainly as generalists and teaching all the required areas of curriculum, will be able to teach, record and report on the progress of each child against the relevant achievement objectives covered. Already there are signs that this has led to a massive increase in workload for primary teachers keen to do the best for each student:

Marking, assessment and report writing take up the equivalent of over an hour per weekday (5.2 hours per week), but in fact much of this is done in weekends (Livingstone, 1994:14).

Curriculum balance, however, is not merely a matter of time. It is also about quality. In primary schools, particularly in the early years, it could be argued that an "unbalanced" curriculum is quite legitimate. Mastery of the basic skills receives the greatest emphasis in the early years of primary schools. A cross-curriculum approach is taken, with skills such as literacy taught through science, social studies and language themes.

The emphasis on basic skills assists children's learning in all areas, and the cross curriculum approach is an attempt to cover "content" as well.

To date this approach has worked well, particularly in the literacy levels achieved by primary students (Elley, 1992). But there may be important questions raised as to whether this is appropriate for the development of all basic skills at primary schools solely in order to achieve a "broad and balanced" education.

McDonald et al. (1992) provide a case study analysis of the amount of time spent on different learning activities in the first three years of a child's school life. Almost 50 percent was spent on literacy compared with 13 percent on mathematics - not a surprising feature of primary schools when "there is little dissent about the centrality of language in the learning process with children doing their learning, and thinking, through language" (Sammons et al., 994:57).

And as McDonald et al. (1992) found, for primary schools, the curriculum is not divided into neat packaged subjects. Science, for example, may not be confined to a lesson labelled as such.

Despite the widespread support for balance and breadth to children's educational experience, the capacity of primary schools to 
teach all subjects must be considered realistically The expectation that, in a variety of subjects, the learning tasks can be exactly matched to the needs and abilities of every student in the class at any one time is hopelessly unrealistic.

The problem of curriculum overload is inevitable if the curriculum is seen as separate subjects. Each of the "subject" specific groups would stake a claim on limited curriculum time available (Barber, 1993:16). Curriculum overload, then, is the sum of the subject parts which constitute an unmanageable whole for the typical primary teacher.

A Wellington region survey of the workloads of primary school teachers (Livingstone, 1994) found primary teachers' view of their ability to increase their workloads is already having disturbing effects on their morale:

Teachers' perceptions of their workload were that it had been consistently and rapidly increasing over the last five years since 1989.

Their copious and often trenchant verbatim comments gave a sense of a group of committed people under severe and mounting pressure.

And among the areas which generated most stress for teachers were:

... the almost simultaneous implementation of many new curricula, and the over-rapid way in which this was being done...

Dearing (1993) proposed a "slimmed-down" version of the curriculum for schools in England and Wales in an attempt to reduce the overload of the curriculum, and there has also been interest in lengthening the school day. Would lengthening the school day, the school week, or school year relieve the problem of curriculum overload? It seems unlikely. The culture of schools and of teaching suggests that teachers would devote extra time to those subjects that were to be assessed.

\section{Conclusion}

There was little public debate in New Zealand on the proposed framework model (Elley, 1993:38) at the primary school level prior to the release of the draft New Zealand National Curriculum Discussion Document (Ministry of Education, 1991). Neither did the introduction of assessment at key transition points (Ministry of Education, 1993a:25) appear to be the solution to any stated problem within primary schools which has been the subject of particular debate or investigation. While there are no rational grounds on an educational basis evident for the organisation of curriculum and assessment as proposed by the framework, if the intention is to provide information about schools to allow for parental choice and competition between schools, then the rationality for the model used in the framework can clearly be seen.

The successful implementation of any policies in education depends largely upon teachers who have to carry them out (Brehony, 1990:122). But the Government's lack of commitment to the status of primary school teachers and the more attractive funding and staffing levels at secondary school must have a negative effect on primary teacher motivation and morale.

Primary schools in 1994 were doing a lot of things right. While there were problems, not all of them were due to inadequate resources (for example, an imprecise notion of child-centredness). There is much at stake for New Zealand primary schools if they are to maintain the distinctive character for which they are internationally renowned.

Overall, teachers find themselves in a dilemma. Although they like the general idea of the framework, now that the accompanying statements are being developed they recognise a wide range of problems. How are primary teachers going to reconcile good practices, the variety of classroom realities and constraints, and the demands of the New Zealand national curriculum framework?

If one looks back at history for the past 50 years, primary teachers have successfully worked within a system that had a secondaryorientated, examination-dominated education framework. Within that period primary teachers did manage to establish child-centred curriculum/pedagogy. They have established sound practices informed by research literature. If primary teachers are clear in their opposition, can successfully resist league tables, and can articulate to parents their reasons for, and the costs of doing so, then they may be able to maintain a successful child-centred model for learning.

\section{References}

Alexander, R., Rose, J., Woodhead, C. "Curriculum Organisation and Classroom Practice in Primary Schools", A Discussion Paper, London: DES, 1992

Barber, M. and Graham, D. (eds). Sense and Nonsense and the National Curriculum, London: Falmer Press, 1993.

Bennett, N., Summers, M., and Askew, M. “Knowledge for teaching and teacher performance", in A. Pollard (ed), Lookbefore you leap? Research Evidence for Curriculum at Key Stage Two, 1994. 
Black, P. "Pressing priorities", Times Educational Supplement, 23 April, 1993.

Brehony, K. J. "Neither rhyme nor reason: primary schooling and the national curriculum", in M. Flude and M. Hamer (eds), The Education Reform Act 1988. Its Origins and Implications, London: The Falmer Press, 1990.

Campbell, J. and Emery, H. "Curriculum policy for key stage 2: possibilities, contradictions and constraints", in A. Pollard (ed), Look Before You Leap, 1994.

Chapman, J., Angus, L., Burke, G., Wilkinson, V. “Improving the Quality of Australian schools", Australian Education Review No.33, Victoria: ACER, 1991.

Codd, J., Harker, R., Nash, R. (eds), Political Issues in New Zealand Education, 2nd ed., Palmerston North: Dunmore Press, 1990.

Crooks, T. "The impact of classroom evaluation practices on students", in Review of Educational Research, Vol 58 (4), 1989: 438-481.

Dearing, R. The National Curriculum and its Assessment: Interim Report, York: NCC \& SEAC, 1993.

Donn, M. and Bennie, N. "The National Curriculum of New Zealand”, in Bulletin No.5, May, Wellington: Ministry of Education, 1992.

Dweck, C. "Motivation", in A. Legislate and R. Glaber, Foundations for a psychology of education, Hillsdale: Lawrence Erlbaum Associates, 1989.

Elley, W. How in the world do students read? IEA study of reading literacy, Hamburg: 1EA, 1992.

Elley, W. "Curriculum reform: forwards or backwards?", in H. Manson, (ed), New Zealand Annual Review of Education, 3: 1993, Wellington: VUW, 1993.

Elmore, R. F. and Fuhrman, S. H. (eds). "Governing curriculum: changing patterns in policy, politics, and practice", in The governance of curriculum, Virginia: ASCD, 1994.

Gipps, C. “The TGAT report: trick or treat”, Forum, Vol.31, No.1, 1988:4-7.

Hicks, J. "Pupil profiling and the primary school: a review of the issues", Educational review, Vol 38, No.1, 1986:21-30.

Irwin, M. Curriculum, assessment and qualifications. An evaluation of current reforms, Wellington: NZ Business Roundtable, 1994.
Istance, D. and Lowe, J. "Schools and quality: the concept and concern", in J. Chapman, L. Angus, G. Burke, V. Wilkinson, Improving the quality of Australian schools, 1991.

Lange, D. Tomorrow's schools: The Reform of Education Administration in New Zealand, Wellington: Government Printer, 1988.

Lee, G. and Lee, $\mathrm{H}$ "Examinations and the New Zealand school curriculum: past and present", Delta Research Monograph No.12, Palmerston North: Massey University, 1992.

Livingstone, I. D. "The Workloads of Primary School Teachers", A Wellington region survey, Wellington: Chartwell consultants \& NZEI, 1994.

McDonald, G., Clarke, V, Kidman, J. The first three years: new entrants to J3, Wellington: NZCER, 1992.

Ministerial working party "Assessment for Better Learning", A public discussion document, Wellington: Department of Education, 1989.

Ministry of Education. Draft New Zealand Discussion Document, Wellington: Learning Media, 1991.

Ministry of Education. The New Zealand Curriculum Framework, Wellington: Learning Media, 1993a.

Ministry of Education. English in the New Zealand Curriculum Draft, Wellington: Learning Media, 1993b.

Mitchell, D., McGee, C., Oliver, D. "Hear our Voices", Final Report of Monitoring Today's Schools Research Project, Hamilton: University of Waikato, 1993.

Moore, R. and Ozga, J. (eds). Curriculum Policy, United Kingdom: Pergamon Press, 1991.

New Zealand Educational Institute. "NZEI response to the National Curriculum Discussion Document draft", Wellington: NZEI, 1991.

New Zealand Educational Institute. "NZEI response to the English in the New Zealand curriculum draft", Wellington: NZEI, 1994a.

New Zealand Educational Institute "Project Maths - a survey on the implementation of the mathematics curriculum statement", Unpublished, 1994b.

New Zealand Treasury. "Government Management", Brief to Incoming Government, Vol II, Education issues, Wellington, 1987. 
OECD. Schools and Quality. An International Report, Paris: OECD, 1989.

OECD. The Curriculum Redefined: Schooling for the 21st Century, Paris: OECD, 1994.

OFSTED. OFSTED response to SCAA consultation on draft proposals for the national curriculum, London: OFSTED, 1994.

Pollard, A. (Ed.), Look Before You Leap? Research Evidence For Curriculum At Key Stage Two, London: Tufnell Press, 1994.

Ramsay, P, Hill, D., Harold, B., Lang, C., Patara, L., Yates, R. “Eighteen Schools: the Baseline study", School-based development project, Occasional paper No.1, Hamilton: University of Waikato, 1994.

Richardson, R. Speech to Women's division of Federated Farmers 47th inter-provincial conference, 11 Feb, 1987.

Sammons, P, Lewis, A., MacLure, M., Riley, J., Bennett, N. and Pollard, A. "Teaching and learning processes" in A. Pollard (ed), Look Before You Leap? Research evidence for curriculum at key stage two, 1994.

Sutton, R. "Striking similarities", in Education, 28 October, 1994: 334-335.

Taskforce to Review Education Administration. Administering for Excellence (Picot Report), Wellington: Government Printer, 1988.

Weston, P, Barrett, E., Jamison, J. The quest for coherence. Managing the whole curriculum, Slough: NFER, 1992.

Wylie, C. Self Managing Schools in New Zealand: The Fifth Year, Wellington: NZCER, 1994.

Wylie, C. \& Smith, L. Learning to Learn. Children's Progress Through the First Three Years of School, Wellington: NZCER, 1993.

\section{Acknowledgements}

This work would never have been completed without the encouragement and support of many friends and colleagues. My appreciation and thanks go in particular to: the library staff at NZEI, Ann Ballantyne, Ruth Mansell, Rosslyn Noonan, Cathie Penetito, Penny Pruden and Dr Cathy Wylie.

The views in this chapter are presented from a personal perspective and do not necessarily reflect those of NZEI:Te Riu Roa.

\section{The author}

Sandra Aikin is currently employed as Senior Officer, Teaching and Learning at the New Zealand Educational Institute. Her work involves close liaison with practising primary school teachers in matters dealing with curriculum and assessment and other professional issues. 